\title{
Aggregating Labour Supply and Feedback Effects in Microsimulation*
}

\author{
John Creedy \\ University of Melbourne
}

Alan Duncan

University of Nottingham, IFS and MIAESR

*This research has been supported by an ARC SPIRT grant. Addresses for correspondence: Department of Economics, University of Melbourne, Parkville, Victoria 3052, Australia. email: jcreedy@unimelb.edu.au and; School of Economics, University of Nottingham, University Park, Nottingham NG7 2RD, United Kingdom; e-mail: alan.duncan@nottingham.ac.uk 


\begin{abstract}
This paper extends behavioural microsimulation modelling so that third round effects of a policy change can be simulated. The first round effects relate to fixed hours of work, while second round effects allow for changes in desired hours of work at unchanged wages. These allow for endogenous changes to the distribution of wage rates resulting from the labour supply responses to tax changes. This is achieved using the concept of an aggregate 'supply response schedule', which identifies the extent to which average labour supply responds to a proportional change in wage rates. The third round effect is obtained after re-running a microsimulation model with a suitable modification to individuals' wage rates. The method is illustrated using the MITTS behavioural microsimulation model.
\end{abstract}

Melbourne Institute Working Paper No. 15/01

ISSN 1328-4991

ISBN 0734015194

November 2001 


\section{Introduction}

Considerable progress has been made in recent years in developing behavioural microsimulation models for the analysis of tax policy changes. These models are partial equilibrium supply side models in which the wage rate distribution is exogenous. They are designed to examine the effects on government expenditures, taxation and labour supply, allowing for the considerable complexity of individuals' budget constraints and taking into account the heterogeneity of individuals, their personal circumstances and preferences. ${ }^{1}$ To restrict microsimulation models to the supply side of the labour market is not unreasonable, given the enormous difficulties of allowing for general equilibrium effects within models that are able to capture the degree of population heterogeneity, combined with the complexity of tax and transfer systems actually in place (or the difficulty of allowing for sufficient heterogeneity in computable general equilibrium models). However, substantial changes in labour supply as a result of a non-marginal policy change may be expected to give rise to changes in the wage rate distribution, depending on the demand for labour. It would therefore be desirable to have a way of accommodating such changes, at least to some extent. ${ }^{2}$

This paper consider the question of how to take behavioural microsimulation analysis one stage further, by anticipating the possible aggregate effects of tax policy reform on wages. ${ }^{3}$ Given a method of evaluating potential changes to the wage rate distribution, such effects can in turn be fed back into the microsimulation model in order to obtain adjusted labour supply responses and expenditure estimates. The proposed method involves a multi-stage procedure in which the simulated labour supply effects of a policy change are aggregated and combined with extraneous information about the demand side of the labour market. ${ }^{4}$

It may be thought that a behavoural microsimulation model could be used to generate, by a simple numerical process of aggregation, a suitable aggregate labour supply schedule that could be combined with an aggregate demand function, either

\footnotetext{
${ }^{1}$ For a suvery of methods of dealing with labour supply responses in microsimulation models, see Creedy and Duncan (2001).

${ }^{2}$ Bergmann (199) discussed microsimulation models in which aggregate unemployment is generated, resulting from job search behaviour in the presence of unemployment insurance. However, all considerations relating to wage levels (on either supply or demand sides of the market) were ignored.

${ }^{3}$ The analysis remains static in the sense that cross-sectional information only is used and individuals are not treated as forming expectations about future wages and prices, or optimising within a life-cycle framework

${ }^{4}$ Alternatively, it is possible to consider the suitably aggregated output from a behavioural microsimulation model as providing information which may be fed into a general equilibrium model that is unable to deal with such population heterogeneity.
} 
estimated econometrically or generated by a general equilibrium model. However, a straightforward correspondence between the output from a microsimulation model and a conventionally defined aggregate supply curve is not possible. A number of aspects of the treatement of aggregate labour supply are discussed in section 2 . The procedure suggested in this paper for simulating feedback effects is presented in section 3. An example using the Melbourne Institute Tax and Transfer Simulator (MITTS) for Australia is presented in section $4 .^{5}$

\section{Aggregate Labour Supply}

This section discusses the problems of aggregating labour supply and explains why no attempt is made here to produce a synthetic aggregate supply function. The first subsection stresses the complexities for aggregation arising from piecewise-linear budget constraints. The second subsection briefly discusses macroeconomic approaches and finally the aggregation problem is formally stated.

\subsection{Individual Labour Supply}

The standard microeconomic approach to the analysis of labour supply involves maximisation of a direct utility function $U\left(c_{i}, h_{i} ; X_{i}\right)$, where $h_{i}$ and $c_{i}$ represent hours worked and consumption (or net income, where the price index is normalised to unity) for an individual $i$ with characteristics $X_{i}$, which includes non-wage income, subject to some budget constraint. This constraint is typically piecewise-linear so the individual faces a variety of net wage rates. The actual net wage depends on the chosen position on the budget constraint and is therefore, like the number of hours worked, endogenous. However, an interior (tangency) solution can be regarded as if it were generated by a linear constraint of the form

$$
w_{n} h_{i}+\mu=c_{i}
$$

where $w_{n}$ and $\mu$ represent the appropriate net wage rate and virtual income respectively, define as the net income at $h_{i}=0$, for the relevant linear segment extended to the axis. An interior solution takes the form, $\widetilde{h}_{i}=\widetilde{h}_{i}\left(w_{n}, \mu\right)$ and is relevant for a strictly limited range of gross wages, $w$. For corner solutions, the virtual wage is used, corresponding to the slope of the indifference curve at the combination of $h_{i}$ and $c_{i}$. After consideration of all possible interior and corner solutions generated by a piecewise linear tax function, the individual's labour supply function, defined over

\footnotetext{
${ }^{5}$ The MITTS model is described in Creedy, Duncan, Harris and Scutella (2002).
} 
the whole range of variation in the gross wage, $w$, takes the general form

$$
h_{i}^{*}=h\left(w ; X_{i}, T\right)
$$

where $T$ refers to the complete tax and transfer system which generates the nonlinear constraints facing individuals. ${ }^{6}$ The shape of this function is not straightforward, though it is made up of segments based on the form $\widetilde{h}_{i}\left(w_{n}, \mu\right)$. The nonlinearity of budget constraints gives rise to individual labour supply functions displaying considerable variation in the wage elasticity of hours supplied. Explicit consideration must be given to the extensive margin (at which movements into or out of employment occur) and the intensive margin (involving changes in the level of hours worked among those employed). ${ }^{7}$ This raises severe problems for aggregation, as can be seen by considering an individual supply function.

It is important to distinguish between the wage elasticity defined with reference to the gross wage and that in terms of the net wage. The latter is most often reported in empirical microeconometric studies of labour supply, but the former is the more useful concept, taking full account of the endogeneity of the net wage. To illustrate, consider a hypothetical function applying to interior solutions, giving $\widetilde{h}_{i}=\widetilde{h}_{i}(w, \mu)$ of the form ${ }^{8}$

$$
\widetilde{h}_{i}(w, \mu)=A w^{\beta_{1}} \mu^{\beta_{2}},
$$

The parameter $\beta_{1}>0$ represents the constant wage elasticity for this model. If the individual faces a simple linear budget constraint, the function $\widetilde{h}_{i}(w, \mu)$ gives an accurate description of the hours responses to a change in the wage rate, for all $w>w_{0}$, whereby $h_{i}>0$.

To show the distorting effects of a nonlinear tax and transfer schedule on an ostensibly constant elasticity model of labour supply, suppose individuals face a threesegment piecewise-linear budget constraint. ${ }^{9}$ They also incur fixed costs when working. The labour supply function $h_{i}^{*}=h\left(w ; X_{i}, T\right)$ is discontinous at the point of entry

\footnotetext{
${ }^{6}$ The function must ideally be consistent with utility maximisation, allowing for the fact that individuals may be simulated to change the number of hours worked quite considerably in response to some policy reform. A first requirement is that (2) satisfies the integrability conditions. As derived by Hurwitz and Uzawa (1971), these require (for necessity and sufficiency) the Slutsky matrix to be symmetric and negative semi-definite; for further discussion, see Deaton and Muellbauer (1980, pp.89-93) and Stern (1986, pp.145-146). This requires the wage response of the compensated labour supply to be non-negative; that is, $\frac{\partial h}{\partial w}-h \frac{\partial h}{\partial \mu} \geq 0$.

${ }^{7}$ Heckman (1993) considered that in examining welfare reforms, the extensive margin is the more important.

${ }^{8}$ This labour supply function is consistent with a homothetic preference specification.

${ }^{9}$ Such kinks might occur, for example, if a higher tax rate applies when earnings exceed some threshold amount, say $E$.
} 
Table 1: Labour Supplies and Elasticities with Nonlinear Taxation

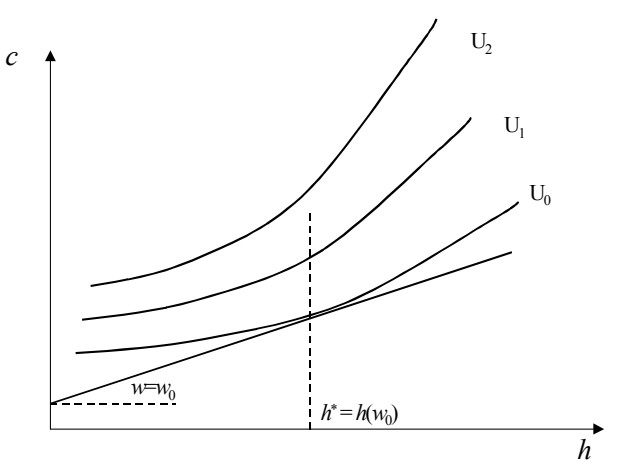

indifference map (linear taxes)

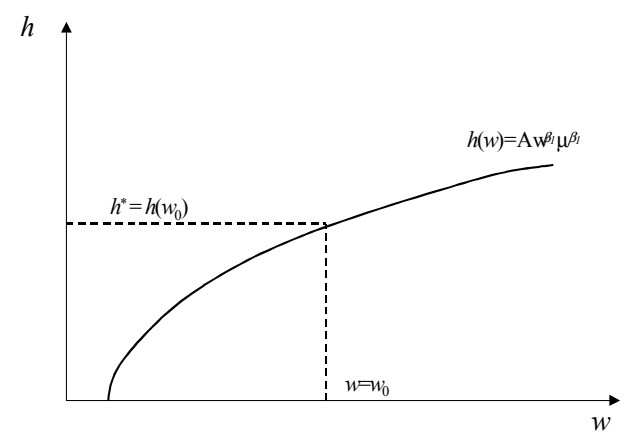

labour supply (linear)

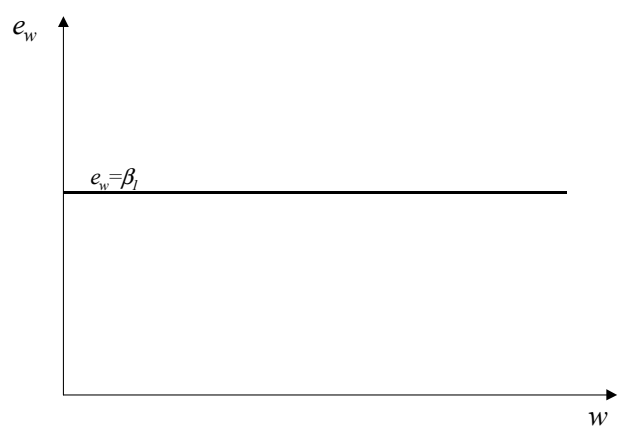

wage elasticity (linear)

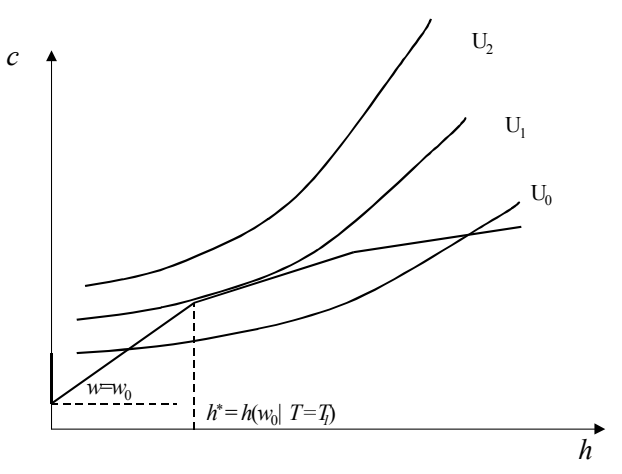

indifference map (nonlinear taxes)

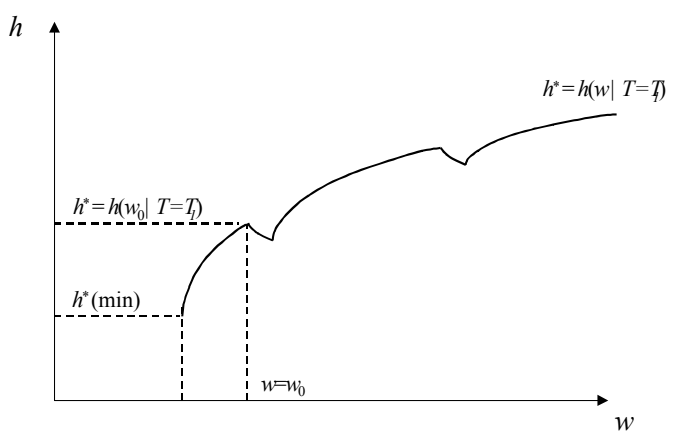

labour supply (nonlinear taxes)

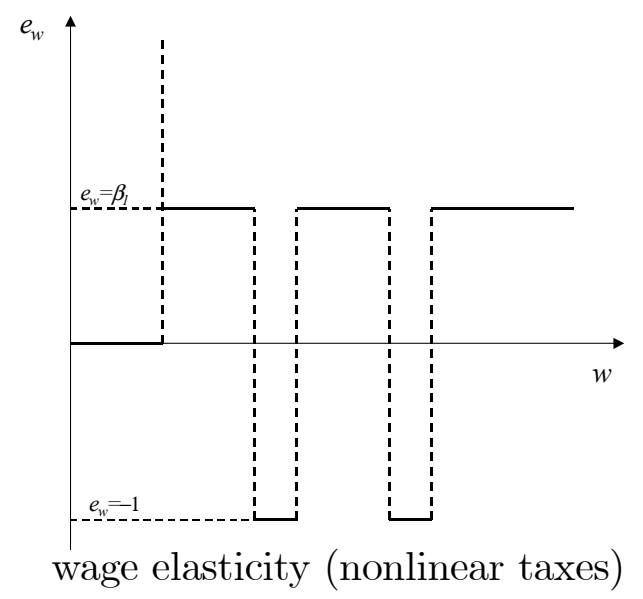


into the labour market. Furthermore, for certain wage rate intervals which place the worker on one of the kinks in the budget constraint, the relationship between wages and hours is negative. ${ }^{10}$ Hence the net wage elasticity bears only a loose resemblance to the effect of a proportionate gross wage change, given the nonlinearities of the budget schedule. This type of phenomenon is illustrated by the various figures in Table 1. The method proposed below is fully able to deal with these responses at the individual level.

\section{$2.2 \quad$ Aggregate Supply Functions}

The conditions under which aggregate observations on labour supply and commodity demands, as functions of some index of prices and wages, can be regarded as being consistent with individual optimisation, are very strong. For example, the use of a representative agent framework was examined in detail by Deaton and Muellbauer (1980) and, in the context of labour supply in particular, by Muellbauer (1981). Furthermore, the conditions obtained by Muellbauer abstract from corner solutions which, as shown above, are of fundamental importance in microsimulation modelling in view of the piecewise-linearity of budget constraints in practice.

In models of labour supply based on aggregate time series data, it is therefore extremely difficult to deal appropriately with heterogeneity, either of individual circumstances or of responses to policy reform. Most aggregate studies tend to be based on the presumption that individual heterogeneity of responses 'average out' in aggregate, to leave a pure price, tax or wage response to a change in economic circumstances. Such an argument is entirely pragmatic.

An example of the treatment of aggregate labour supply in macroecomic models which are underpinned by a microeconomic foundation in optimising behaviour is provided by the intertemporal substitution model, following the early work of Lucas and Rapping (1969). ${ }^{11}$ The model is based on the argument that individuals form expectations about future real wages, in relation to current wages, based on movements in commodity prices. If real wages are considered to be high relative to expected future wages, current labour supply increases as a result of intertemporal substitution. Individual behaviour is thus explicitly linked to a life-cycle labour supply and commodity demand model. The degree of intertemporal substitution thereby affects the variability in labour supply, and therefore unemployment, over time. Empirical

\footnotetext{
${ }^{10}$ This happens because hours are adjusted down as wages increase, in order for the individual to remain on some earnings threshold, so that $w \cdot h=E$.

${ }^{11}$ For examples, see also Altonji $(1982,1986)$. Kennan (1988) examines identification issues in detail.
} 
aggregate supply schedules are estimated using time series data on variables such as average hours, real wage rates, and tax payments. However, these models rely on a single individual, involving no explicit treatment of aggregation issues. ${ }^{12}$

\section{$2.3 \quad$ Aggregating Labour Supply}

To see how aggregation problems arise, consider again the individual labour supply function (2) presented above. At the observed wage of $w_{i}$ for person $i$, the predicted labour supply when faced with tax system $T=T_{0}$ is

$$
h_{i}^{*}\left(w_{i}\right)=h\left(w_{i} ; X_{i}, T=T_{0}\right)
$$

One approach to aggregating individual labour supplies might be to predict and sum (or average) such labour supply predictions over a range of wage rages, with each individual being presented with the same wage rate. Using sample weights $g_{i}$ (representing the number of individuals of type $i$ in the population), this would result in an aggregate supply of the form

$$
H^{*}(w)=\left(\sum g_{i}\right)^{-1} \cdot \sum_{i=1}^{n} g_{i} \cdot h\left(w ; X_{i}, T\right),
$$

at some common wage $w$. However, the interpretation of a function which returns the average of a set of individual labour supplies on the presumption that all are given the same wage is unclear. In practice, it would involve predictions of individual labour supplies at wage rates far from their observed wage $w_{i}$. It may be possible to alleviate the second problem by weighting the average to reflect the distance of $w$ from each observed wage $w_{i}$ using some weighting function $K(.)^{13}$. This alternative distance-weighted schedule might take the form

$$
H_{b}^{*}(w)=\left(\sum g_{i}\right)^{-1} \sum_{i=1}^{n}\left(g_{i} . h\left(w ; X_{i}, T\right) \cdot \frac{K\left[b^{-1}\left(w-w_{i}\right)\right]}{\sum_{i=1}^{n} K\left[b^{-1}\left(w-w_{i}\right)\right]}\right),
$$

for some smoothing parameter $b{ }^{14}$

Instead of attempting to define and obtain an aggregate supply function in which total (or average) labour supply is related to some given single or homogeneous wage rate (considered for example as a measure of location of the wage rate distribution),

\footnotetext{
${ }^{12}$ Discussion of the extensive or intensive margin usually involves simply the use in the econometric modelling of either changes in average hours worked or changes over time in the number of individuals; see, for example, Alogoskoufis (1987).

${ }^{13}$ One possibe choice might be a continuous, symmetric kernel function $K(u)$ with characteristics $K^{\prime}(0)=0$ and $\int K(u) d u=1$.

${ }^{14}$ The smoothing parameter $b$ would control the rate at which the weight function $K($.$) falls as$ the distance of $\mathbf{w}$ from $w_{i}$ increases.
} 
the approach suggested in this paper is to give up the objective of producing an aggregate function. Instead, a 'supply response schedule' is defined in a way which measures how labour supply responds to shifts in the distribution of wage rates. This supply response schedule is an entirely numerical construction, based on simulated labour supply responses to wage changes, conditional on a given tax and transfer structure. The supply responses are based on optimising behaviour, allowing for the full complexity of budget constraints and population heterogeneity.

\section{A Multi-stage Procedure}

This section describes a multi-stage procedure used to produce 'third round' effects of a policy change to the tax and transfer system, allowing for the effects on the distribution of wages. First the concept of the supply response schedule is defined. Further subsections describe the various stages involved, shifts in the schedule and the measurement of wage effects.

\subsection{The Supply Response Schedule}

The computation of a supply response schedule involves several stages. First behavioural microsimulation methods are used to simulate individual labour supply responses to a tax or welfare policy reform, taking full account of the detail of the existing tax and welfare system as it affects each individual. These individual labour supply predictions may be calibrated to reflect closely the actual labour supply patterns in a particular sample of micro data at the observed distribution of wage rates.

Next, a weighted average (using weights provided by the cross-sectional survey used) of the individual labour supply responses is calculated. This gives one point on an empirical supply response schedule. This aggregate measure combines individual labour supply predictions at both the extensive and intensive margins. ${ }^{15}$

A supply response schedule, around the calibrated aggregated labour supply, is generated by modelling individual hours responses to a proportionate change in all observed wage rates. That is, the full wage distribution is perturbed, and the aggregate labour supply response to that perturbation is obtained. The perturbation is based on an index $\mathbf{i}_{\mathbf{w}} \in(-1, \infty)$ which replaces each individual's wage $w_{i}$ with an amount $w_{i}\left(1+\mathbf{i}_{\mathbf{w}}\right)$. The aggregate schedule is then build by summing (averaging) individuals' labour supply responses at a given index $\mathbf{i}_{\mathbf{w}}$, giving a function, in per

\footnotetext{
${ }^{15}$ It would be possible to restrict attention to the extensive margin, by predicting the number of workers rather than average total hours.
} 


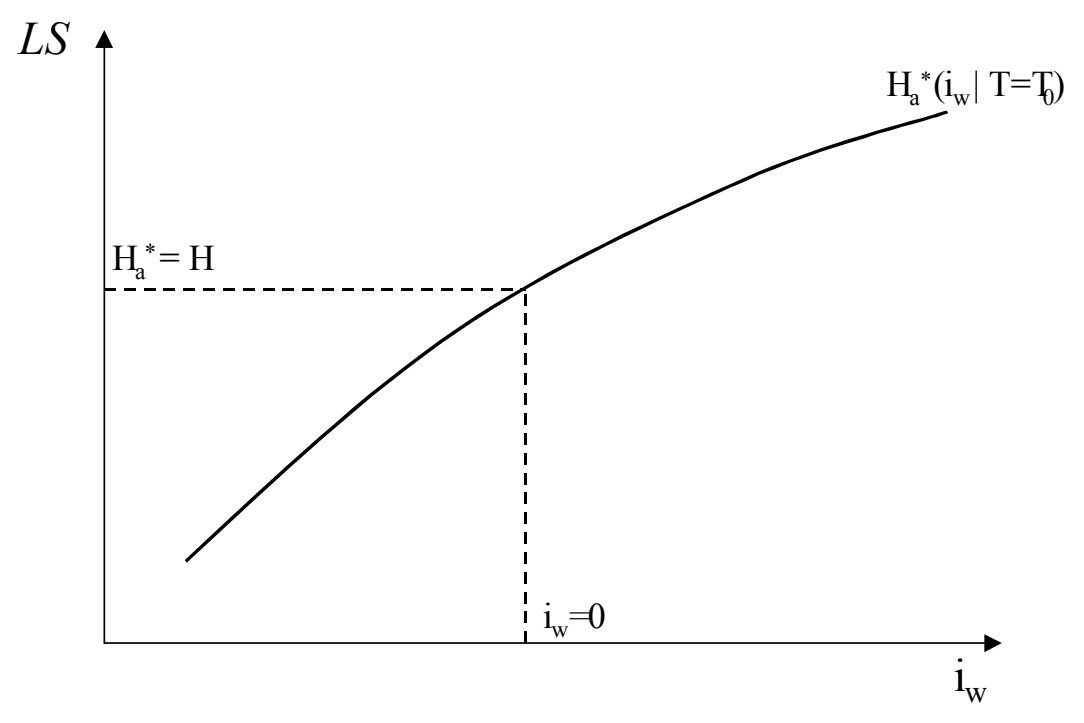

Figure 1: An Aggregate Supply Response Schedule

capita terms, of the form

$$
H_{a}^{*}\left(\mathbf{i}_{\mathbf{w}}\right)=\left(\sum g_{i}\right)^{-1} \cdot \sum_{i=1}^{n} g_{i} \cdot h\left(w_{i}\left(1+\mathbf{i}_{\mathbf{w}}\right) ; X_{i}, T\right)
$$

For $\mathbf{i}_{\mathbf{w}}=0$ this reduces to $H_{a}^{*}(\mathbf{0})=\left(\sum g_{i}\right)^{-1} \cdot \sum_{i=1}^{n} g_{i} \cdot h\left(w_{i} ; X_{i}, T\right)$, which is a simple weighted average of predicted labour supplies at observed wage rates $w_{i}$. For a function $h($.$) which calibrates predicted hours choices to replicate (or closely approxi-$ mate) observed labour supply behaviour $h_{i}$, this predicted aggregate $H_{a}^{*}(\mathbf{0})$ at $\mathbf{i}_{\mathbf{w}}=0$ should be close to the observed aggregate $\bar{H}=\left(\sum g_{i}\right)^{-1} \cdot \sum_{i=1}^{n} g_{i} h_{i}$.

The advantage of this type of supply response schedule, which is quite different from any type of aggregate supply function, is that each point on the schedule is consistent with a distribution of wages together with the underlying tax and transfer scheme and population characteristics. Movement along the supply response schedule may be presented as a shift in the entire wage distribution. This in turn can be fed back to a microsimulation model to preserve the heterogeneity of wage rates on which so much of the detail of microsimulation depends. A schedule of this type is shown in Figure 1.

This is very different from the aggregate supply schedules preduced at the macroeconomic level, as for example in the literature following Lucas and Rapping (1969), discussed above. These models presume a single consumer who, by definition, works at the intensive margin. If such a model were parameterised using predictions from the microeconometrics literature, the wage elasticity would generally be low. Empir- 
ical studies of labour supply support the view that most action takes place at the extensive margin of labour market participation, where higher elasticities of response are typically estimated. The fact that time series estimates indicate higher elasticities for aggregate models compared with microeconometric models may perhaps result from the fact that aggregate data represent a combination of participation and conditional hours choices.

The supply response schedule is an entirely numerical concept, as it traces the aggregate labour supply resulting from equal proportionate changes in wage rates, conditional on the tax and transfer system and the nature of the population. However, it can be generated directly from a behavioural microsimulation model and provides the information needed in order to produce appropriate feedback effects of tax policy changes.

\subsection{Shifts in the Supply Response Schedule}

Similar methods to those outlined above can be applied to simulate shifts in the supply response schedule resulting from a change in tax or welfare policy. Because the supply response schedule is build from the predictions of a behavioural microsimulation model, the effects of an enormous range of policy reforms could be simulated. These might include, for example, tax rate or threshold changes, adjustments in welfare payment tapers, or increases in the level of family benefits. The type of change is limited only by the level of tax system detail in the microsimulation model.

Suppose there are two tax systems, denoted $T_{0}$ and $T_{1}$. Here $T_{0}$ may represent some benchmark tax system corresponding to a given year's microdata, and $T_{1}$ represents the tax system following a hypothetical policy reform. Let the predicted labour supplies of the $i$ th individual at wage rate $w_{i}\left(1+\mathbf{i}_{\mathbf{w}}\right)$ under systems $T_{0}$ and $T_{1}$, be denoted respectively by $h_{i 0}^{*}\left(\mathbf{i}_{\mathbf{w}}\right)=h\left(w_{i}\left(1+\mathbf{i}_{\mathbf{w}}\right) ; X_{i}, T=T_{0}\right)$ and $h_{i 1}^{*}\left(\mathbf{i}_{\mathbf{w}}\right)=h\left(w_{i}(1+\right.$ $\left.\left.\mathbf{i}_{\mathbf{w}}\right) ; X_{i}, T=T_{1}\right)$. By aggregating the difference between these predictions at any value of $\mathbf{i}_{\mathbf{w}}$ in the manner of (7), a simulation of the shift in overall labour supply when moving from tax system $T_{0}$ to $T_{1}$ is obtained as

$$
\triangle H_{a}^{*}\left(\mathbf{i}_{\mathbf{w}} \mid T_{0}, T_{1}\right)=\left(\sum g_{i}\right)^{-1} \cdot \sum_{i=1}^{n} g_{i} \cdot\left[h_{i 1}^{*}\left(\mathbf{i}_{\mathbf{w}}\right)-h_{i 0}^{*}\left(\mathbf{i}_{\mathbf{w}}\right)\right] .
$$

\subsection{Modelling Feedback Effects}

For a given policy change, the standard microsimulation model can calculate the implications for total expenditure and tax revenue, on the assumption that there are 


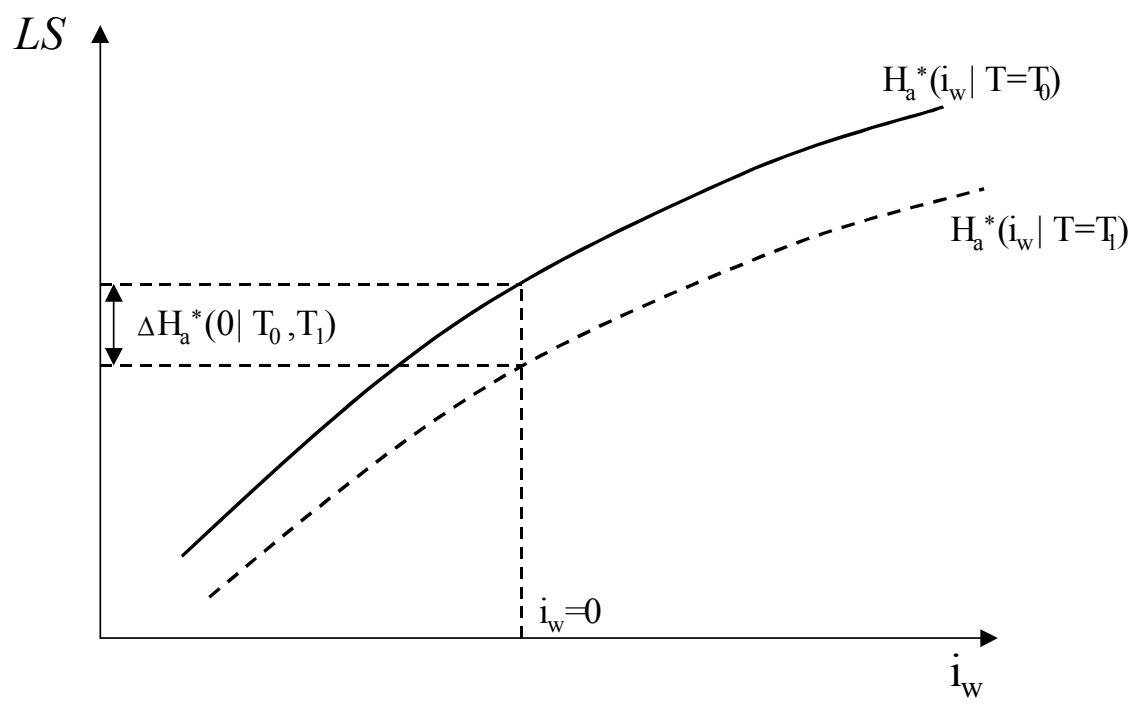

Figure 2: A Shift in The Aggregate Supply Response Schedule

no labour supply responses. ${ }^{16}$ It is useful to refer to such non-behavioural changes in costs as the 'first round' effects of the policy change.

The changes in costs and revenues, allowing for labour supply responses but keeping the wage rate distribution fixed, may be described as the 'second round' effects of the policy change. The second round effect is equivalent to a vertical movement from an initial supply response schedule (under $T_{0}$ in Figure 2) to the revised schedule (for $T_{1}$ ), that is keeping $\mathbf{i}_{\mathbf{w}}=0$.

The previous subsection has described how a shift in the supply response schedule, as a result of a tax and transfer policy change, can be generated. This shift can be used, in combination with information about a corresponding aggregate demand response schedule for labour, to generate a suitable value of $\mathbf{i}_{w}$. This value of $\mathbf{i}_{\mathbf{w}}$ is given by the intersection between the new supply response schedule and the demand response schedule. It can then be factored into a revised behavioural simulation to generate a new set of labour supply responses and costs for the same tax policy change, using a shift in the wage rate distribution. These new responses are referred to as 'third round' responses.

The second round effect of a tax or welfare policy reform is equivalent to the

\footnotetext{
${ }^{16} \mathrm{~A}$ number of static microsimulation models have been used to inform policy in this way. Examoples include the Institute for Fiscal Studies' TAXBEN for the UK, the Economic and Social Research Institute's SWITCH model for Ireland, NATSEM's STINMOD for Australia.
} 


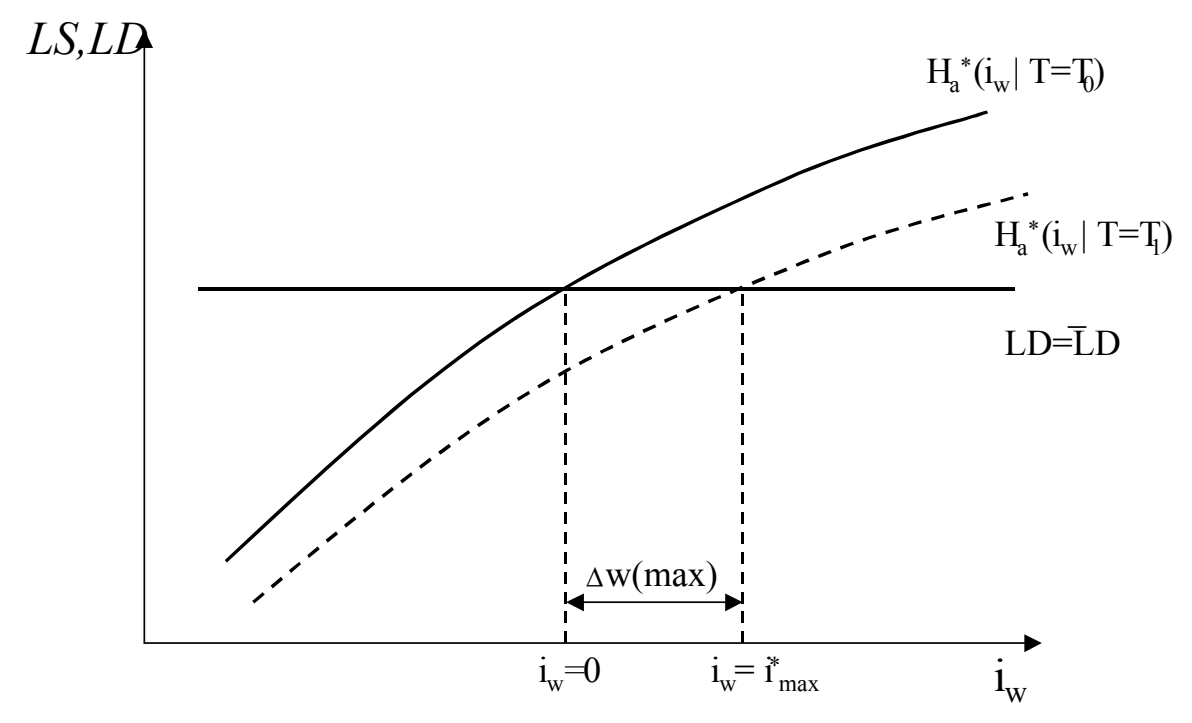

Figure 3: The Wage Response to a Shift in The Supply Response Schedule: Inelastic Demand

interaction of the aggregate supply response schedule with an infinitely elastic labour demand response schedule, so that an increase or decrease in labour supply is absorbed with no changes in the distribution of wage rates. In the absence of further information, it is of interest to consider the other extreme assumption of completely inelastic demand response. That is, if aggregate supply increases following some tax policy reform, then wages must fall proportionately in order to keep employment (aggregate hours) fixed at the initial level. This extreme is considered in the following section.

\subsection{Measuring Wage Effects in Microsimulation}

Consider the extreme assumption whereby the labour demand response schedule is fixed at some level $L D=\overline{L D}$. The shift in the aggregate supply response schedule can be used to simulate a proportionate change in the wage distribution following a tax policy reform. Figure 3 provides an illustration. Suppose that the tax system shifts from $T_{0}$ to $T_{1}$ following a policy reform in a way which causes the aggregate supply response schedule to shift downwards. That is,

$$
H_{a}^{*}\left(\mathbf{i}_{\mathbf{w}} \mid T=T_{1}\right)<H_{a}^{*}\left(\mathbf{i}_{\mathbf{w}} \mid T=T_{0}\right) \text { for all } \mathbf{i}_{\mathbf{w}}
$$




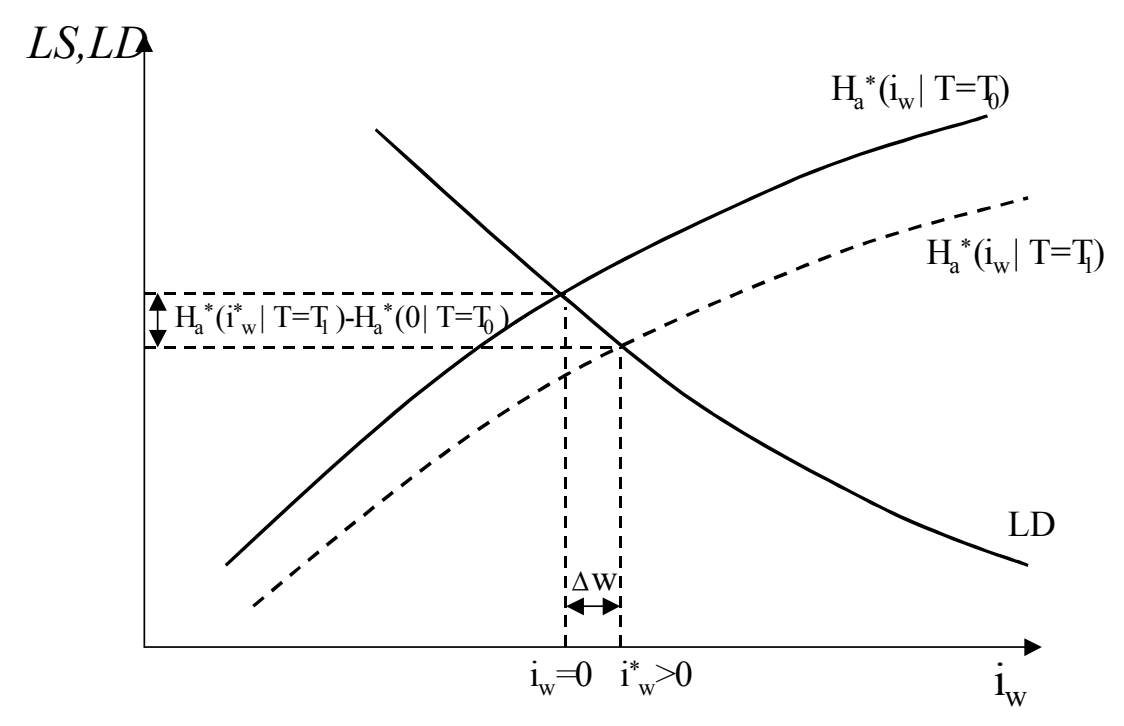

Figure 4: The Wage Response to a Shift in The Supply Response Schedule: Flexible Demand

Under the restriction that demand is fixed at $L D=\overline{L D}$, the supply shift increases the distribution of wages by some measurable proportion $\mathbf{i}_{\max }^{*}$. This factor may then be used to adjust each individual's wage, before being fed back into a revised behavioural simulation, as explained above. The result is the third round simulation in which both labour supply and wages adjust following the introduction of some tax policy reform.

The inelastic demand assumption is an extreme case. With a flexible demand response schedule of the sort shown in Figure 4, the same inward shift in aggregate supply produces movement both in the wage distribution and in equilibrium supply. Under these circumstances, the third-round shift in aggregate supply corresponds to the difference

$$
\triangle H_{a}=H_{a}^{*}\left(\mathbf{i}_{\mathbf{w}}^{*} \mid T=T_{1}\right)-H_{a}^{*}\left(\mathbf{0} \mid T=T_{0}\right),
$$

where $\mathbf{i}_{\mathbf{w}}^{*}$ is the difference (in $\mathbf{i}_{\mathbf{w}}$ space) in the intersections of the aggregate supply response schedules under $T_{0}$ and $T_{1}$ with the aggregate demand response schedule.

The approach can also be applied to separate groups, distinguished for example by education or occupation. This would produce a set of adjustment terms, enabling a change in the dispersion of wage rates to be modelled. A given policy change may produce wage increases for some groups while wages may fall for others, depending on the labour supply and demand effects. 


\section{An Empirical Illustration}

To illustrate the use of aggregate supply response schedules in behavioural microsimulation, this section shows how the Melbourne Institute Tax and Transfer Simulator (MITTS) might be adapted to model the possible effects of tax reform on labour supply and the distribution of wage rates. ${ }^{17}$ In the absence of a labour demand response schedule, the extreme assumption is used that labour demand is fixed at the level of the pre-reform distribution of hours. Suppose that in the Australian tax and transfer system of January 2000, the initial income tax rate is increased from 20 per cent to 25 per cent. The data used for these simulations are drawn from the 1997 Income Distribution Survey (IDS), a large sample of microdata with information on the labour supply, wage rates and demographic characteristics of around 7,000 Australian households.

\subsection{Simulated Aggregate Supply Response Schedules}

The aggregate supply response schedule for the full sample of working-age households was constructed by aggregating individual labour supply predictions from the behavioural microsimulation component, using the formulation (7). Labour supplies both under the baseline January 2000 system, and the reform system incorporating an increase of 5 percentage points in the basic income tax rate, were predicted. Using calibration methods, the simulated average labour supply under the January 2000 system at the observed distribution of wages is broadly equivalent to the overall average labour supply (around 19 hours per week) observed in the data. In Figure 5, this correponds to the point on the first aggregate supply response schedule at which $\mathbf{i}_{\mathbf{w}}=0$. Varying $\mathbf{i}_{\mathbf{w}}$ under the January 2000 system produces the aggregate supply response schedule.

Figure 5 shows that this empirical schedule is positive and monotonic over the range $\mathbf{i}_{\mathbf{w}}=\{-0.5,0.7\} .{ }^{18}$ The corresponding bold line in Figure 6 translates the aggregate supply responses into an empirical wage elasticity schedule. At the distribution of wage rates observed in the data $\left(\mathbf{i}_{\mathbf{w}}=0\right)$, an elasticity of around 0.62 for the full

\footnotetext{
${ }^{17}$ For further details of the MITTS model, see Creedy, Duncan, Harris and Scutella (2002).

${ }^{18}$ The extremes of this range for $\mathbf{i}_{\mathrm{w}}$ cover a reduction of 50 per cent to all wage rates in the sample (at the lower end) to an increase of 70 per cent in all wages (at the higher end). The range can be expanded, although computationally the procedure for generating empirical supply schedules is time-consuming. Figure 5 is a fourth-order polynomial-smoothed approximation to the empirical supply schedule, using data from a series of simulations in which the wage distribution is increased in steps of 5 from 50 to 170 per cent of the current distribution. The procedure in total took around 27 hours on a 700MHz Pentium III using MITTS.
} 


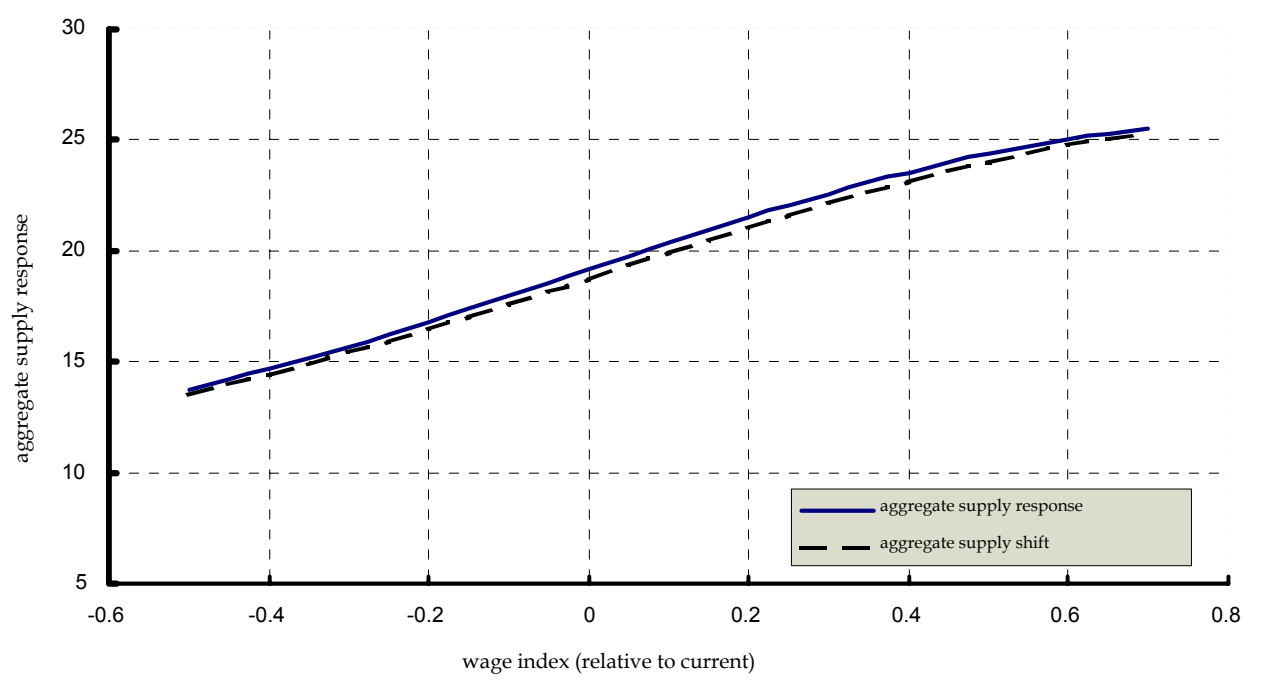

Figure 5: Simulated Aggregate Supply Response Schedules

population is obtained, rising slightly as the distribution of wages increases beyond the observed level before falling for larger perturbations to the wage distribution. At lower wage rates (corresponding to negative $\mathbf{i}_{\mathbf{w}}$ ), the aggregate wage elasticity falls (to around 0.35 when all wages are halved). This decline in the aggregate wage elasticity might be caused in part by an increased reliance on transfer payments, particularly among low wage workers.

The formulation in (8) is used to simulate a shift in the aggregate supply response schedule following an increase of 5 percentage points in the basic income tax rate. In Figure 5, the post-reform schedule (the hashed line) is everwhere below the first schedule. At equivalent wage rates for all individuals in the sample, aggregate labour supply reduces following in the increase in taxes. At the observed distribution of wages, the average reduction in labour supply is around 0.36 hours (equivalent to around $2 \%)^{19}$

\footnotetext{
${ }^{19}$ This might appear relatively small when compared with an apparent reduction of around 7 per cent in the marginal wage (from $w_{i}(1-0.2)$ to $w_{i}(1-0.25)$ for a basic rate taxpayer). However, on closer inspection this tax rate is not realised for all who do not pay tax (those on low incomes and not in work). Moreover, the overall percentage change in net income is much lower than 7 per cent when account is taken of tax-free thresholds and higher tax rates (which remain unchanged following the hypothetical policy reform).
} 


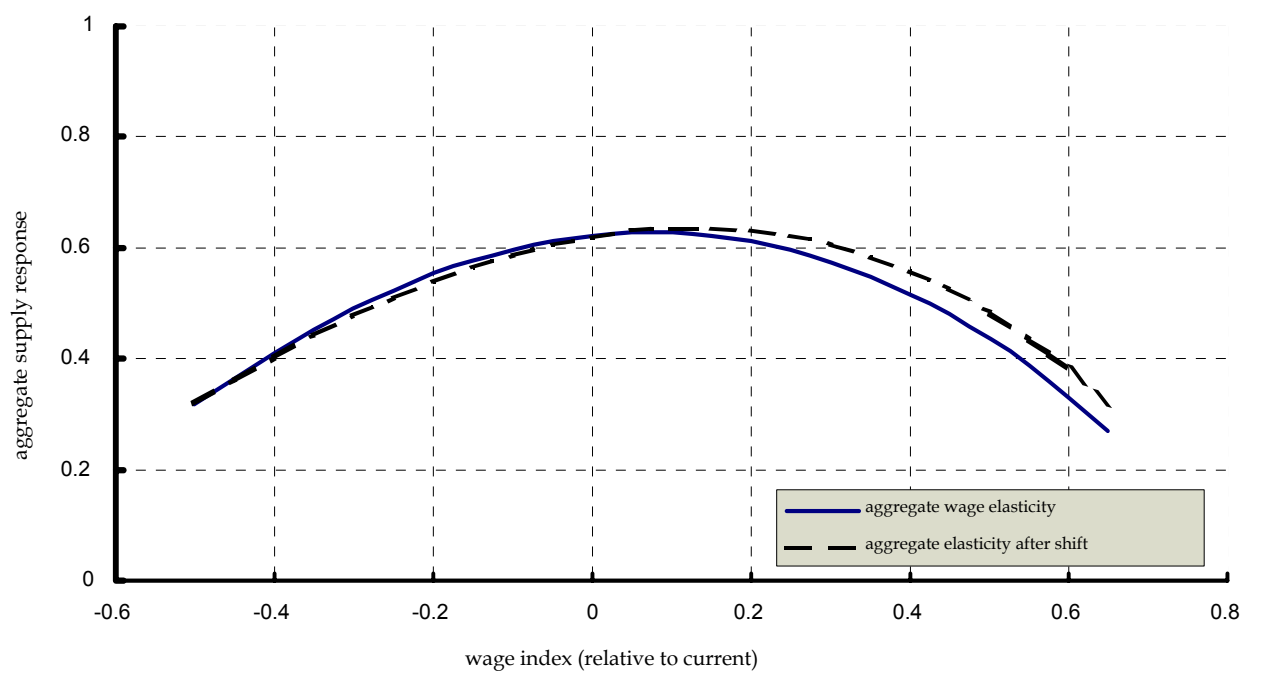

Figure 6: Simulated Aggregate Wage Elasticities

\subsection{Dissagregated Supply Response Schedules}

The multi-stage method of generating aggregate supply response schedules may be extended to simulate the average labour supply responses of particular demographic groups, as suggested above. By averaging the same individual responses over target groups within the sample, rather than over the sample as a whole, it is possible to generate and compare a series of aggregate supply response schedules. Tables 2 to 4 show a series of comparative schedules. In each case, the left-hand panel shows the supply schedule and the right-hand panel translates these responses into average wage elasticities.

Table 2 shows the comparative aggregate supply schedules of high- and loweducation individuals, displaying systematically higher labour supply on average among the higher educated group (in part as a consequence of combining simulated non-participants with workers in the empirical schedules). ${ }^{20}$ The implied pattern of empirical wage elasticities is reversed, with higher elasticities among the loweducation group. This could be a manifestation of Heckman's (1993) observation

\footnotetext{
${ }^{20}$ The high-education group corresponds to those with more than the basic (compulsory) level of education. This comparison was designed to proxy the relative supply response schedules of high and low skill labour in the absence of observations on skill levels for non-working individuals in our sample.
} 
Table 2: Disaggregated Supply Schedules: High/Low Education

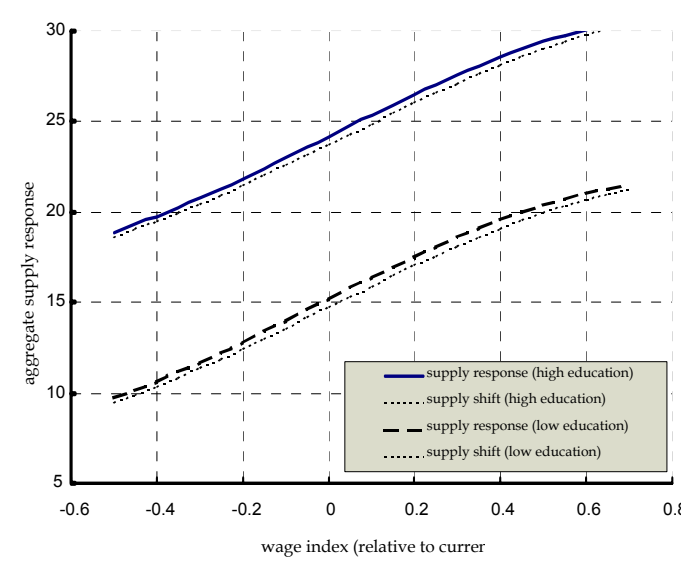

simulated responses

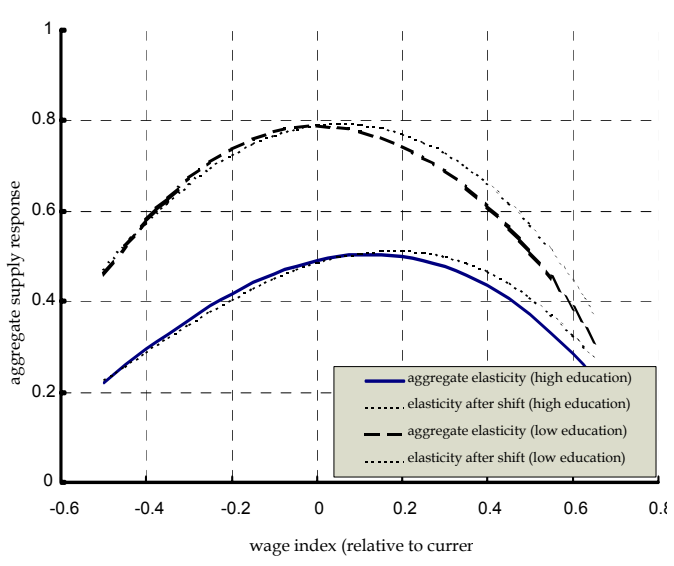

simulated elasticities

Table 3: Disaggregated Supply Schedules: All/Single Parents

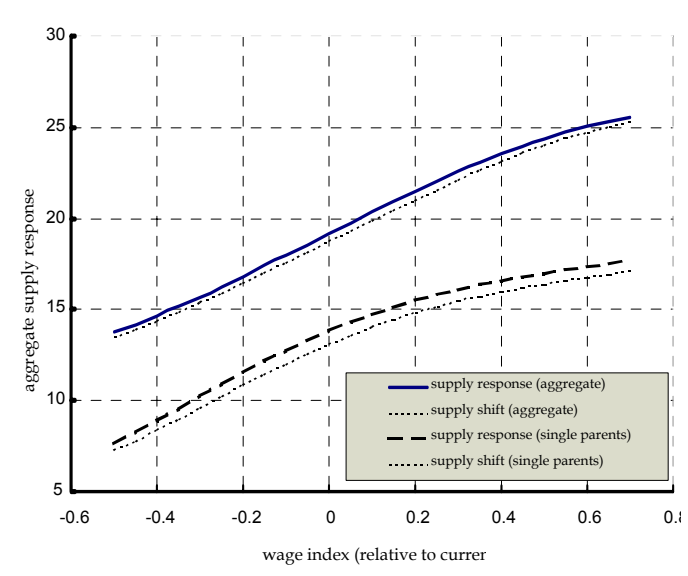

simulated responses

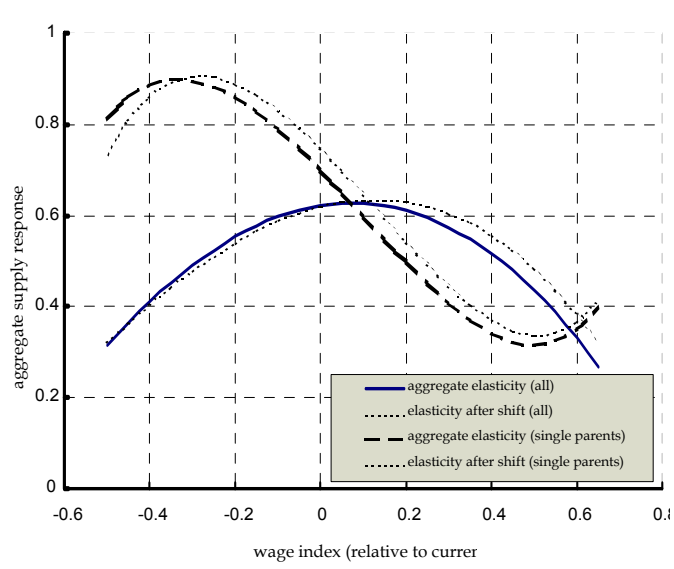

simulated elasticities

that higher labour supply responses are found at the extensive (participation) margin.

Table 3 compares the average supply responses of sole parents with those of the full sample. Average labour supply is systematically lower, a function in part of lower participation rates among sole parents than among other groups in the population. The shift in the aggregate supply response schedule for sole parents is proportionately larger, reflecting an increased sensitivity among this group to changes in the net wage. This fact is borne out by a comparison of empirical wage elasticities, showing increased wage elasticities among sole parent households as wage rates fall (equivalently, as income tax rates rise). Similar comparative patterns emerge when comparing the aggregate supply responses of women and men, as shown in Table 4. 


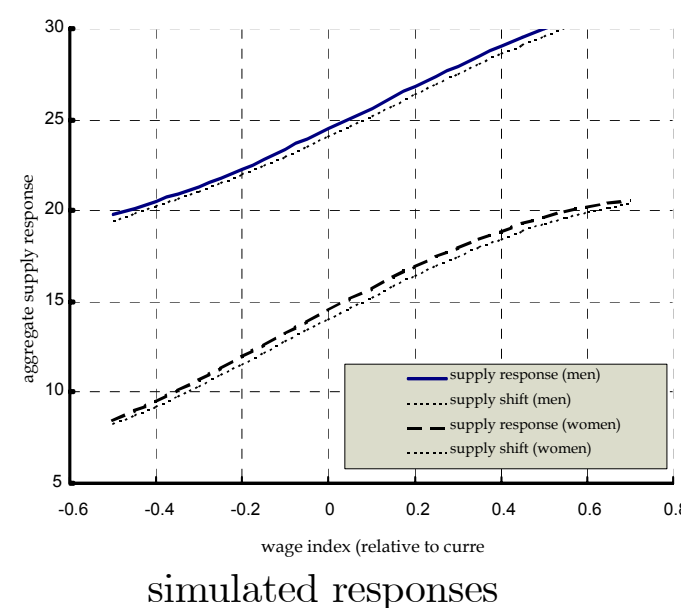

simulated responses

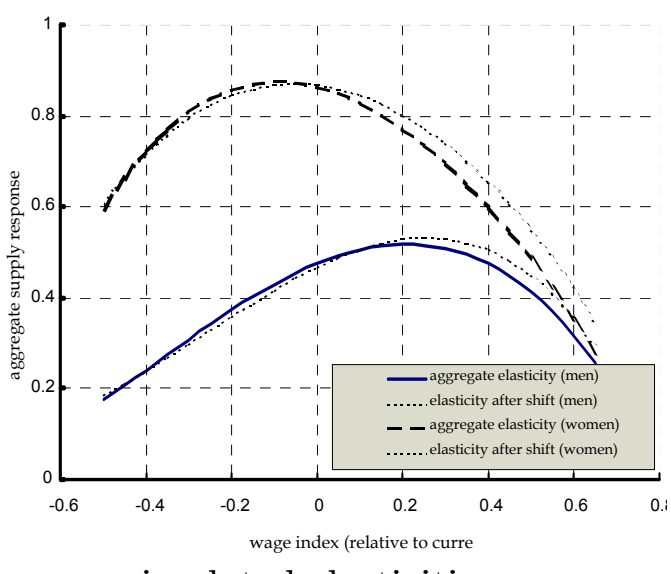

simulated elasticities

\subsection{Simulating Wage Responses to a Policy Change}

The previous section described a method by which to simulate the proportional effects on the wage distribution following a shift in the aggregate supply schedule. Under assumptions regarding the equivalent aggregate labour demand schedule, the intersections of simulated demand and supply might be used to model the extent to which wages might adjust followong a policy reform. With inelastic labour demand, the extent of the proportionate shift in wage rates could be simulated by measuring the horizontal distance $\mathbf{i}_{\max }^{*}$ between the two aggregate supply schedules at the pre-reform level of aggregate supply; see Figure 3. With a flexible demand response schedule, the full effect of the policy reform comprises shifts both in the wage distribution and in the equilibrium level of supply/demand; see Figure 4. We consider both cases in our empirical simulations. ${ }^{21}$

For the empirical simulations described earlier, the third-round effects of the 5 percentage point increase in income tax can be measured under alternative hypothetical specifications of aggregate labour demand. We consider two alternatives in particular; the first assumes that demand is completely inelastic, so that $L_{d}\left(\mathbf{i}_{\mathbf{w}}\right)=L_{0}$ in the earlier formulation. The second assumes that $L_{d}\left(\mathbf{i}_{\mathbf{w}}\right)=L_{0} \cdot\left(1+\mathbf{i}_{\mathbf{w}}\right)^{\varepsilon_{d}}$ with elasticity $\varepsilon_{d}=0.5$, a central figure in the range of labour demand elasticities typically reported in the empirical literature. ${ }^{22}$

\footnotetext{
${ }^{21}$ For illustration, we combine the aggregate supply response schedule with a constant elasticity aggregate demand schedule of the form $L_{d}\left(\mathbf{i}_{\mathbf{w}}\right)=L_{0} \cdot\left(1+\mathbf{i}_{\mathbf{w}}\right)^{\varepsilon_{d}}$, where $\varepsilon_{d}$ represents the aggregate demand elasticity, and $L_{0}$ corresponds to the equilibrium level of aggregate labour at $\mathbf{i}_{\mathbf{w}}=0$ (the pre-reform wage distribution).

${ }^{22}$ see Hamermesh (1993).
} 


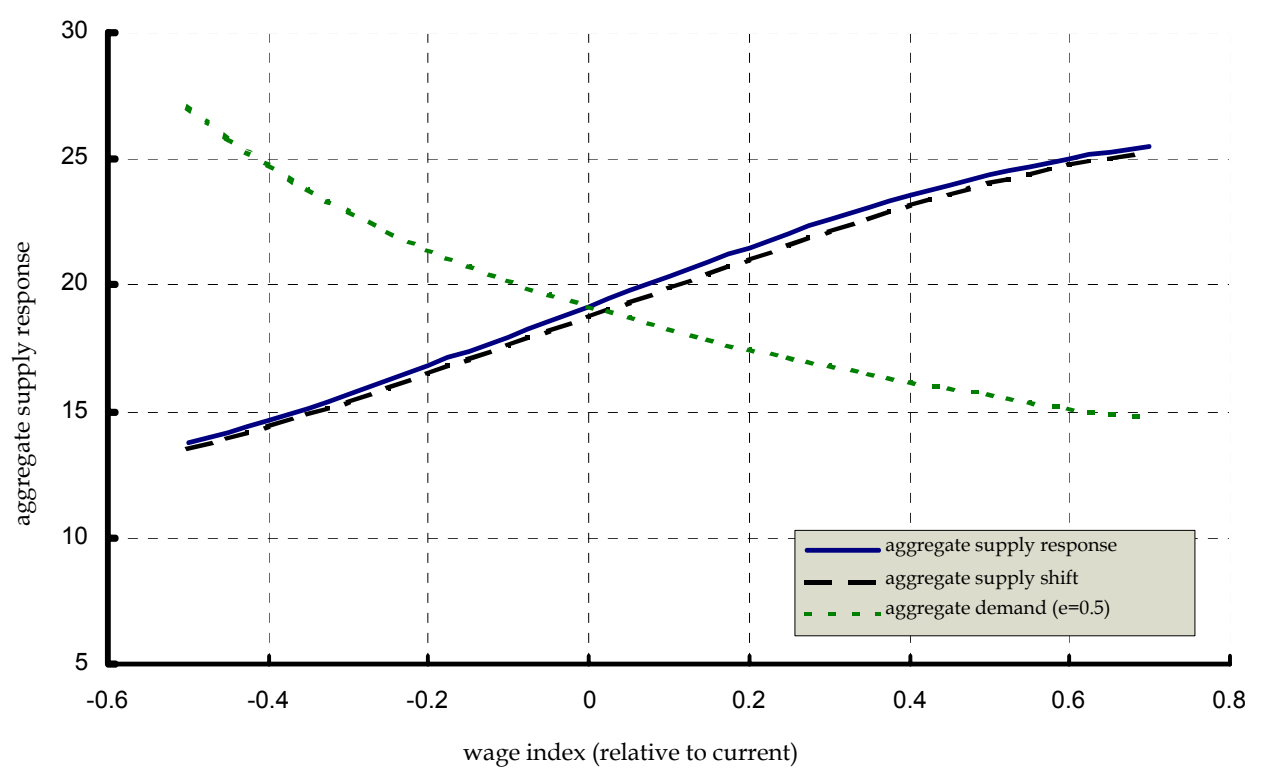

Figure 7: Aggregate Demand and Supply Response Schedules

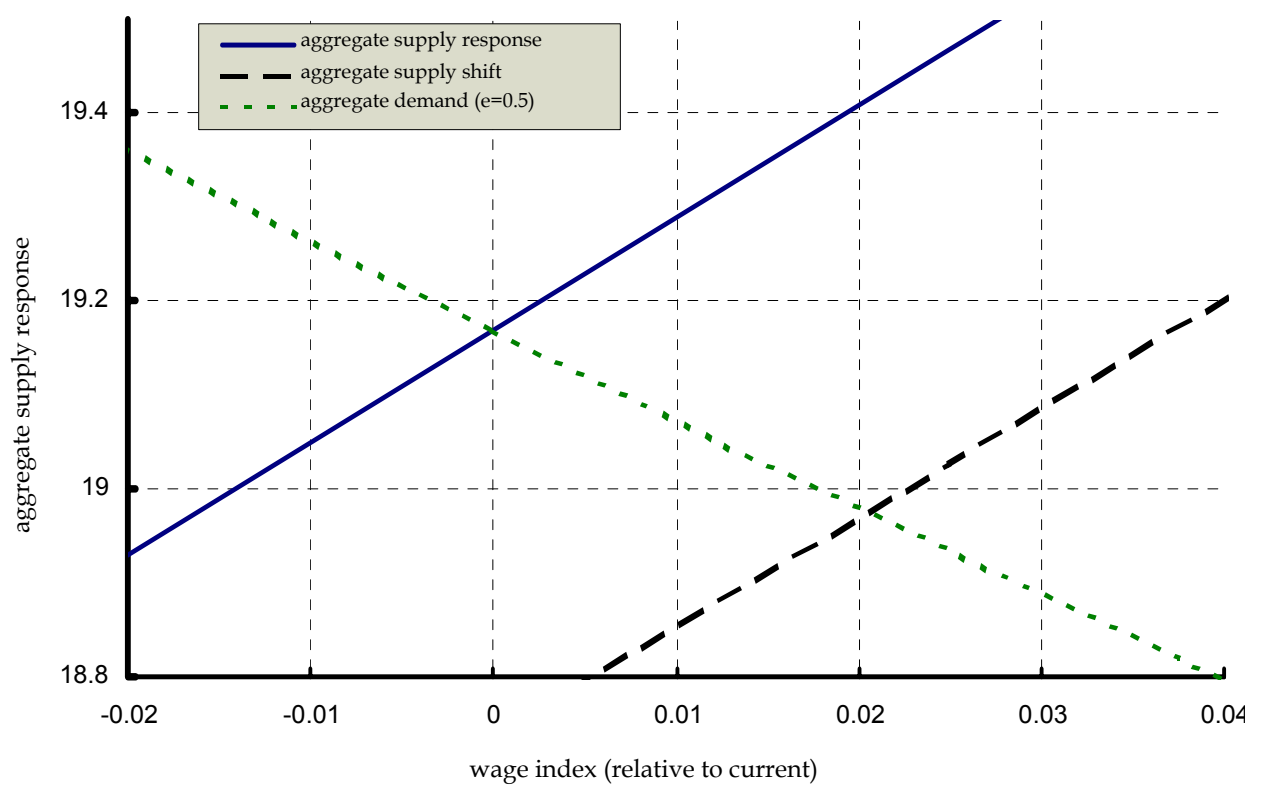

Figure 8: Aggregate Demand and Supply Response Schedule: detail 
Table 5: First, Second and Third Round Effects of Tax Reform

\begin{tabular}{lcccc}
\hline \hline Percentage change in: & First round & \multirow{2}{*}{ Second round } & \multicolumn{2}{c}{ Third round } \\
\cline { 3 - 5 } & & & $\varepsilon_{d}=0$ & $\varepsilon_{d}=0.5$ \\
\hline Income tax revenue & $+9.1 \%$ & $+7.9 \%$ & $+13.4 \%$ & $+11.7 \%$ \\
Allowance costs & - & $+2.8 \%$ & $-0.5 \%$ & $+0.1 \%$ \\
Aggregate labor supply & - & $-1.9 \%$ & $-0.1 \%$ & $-1.0 \%$ \\
Wage rates & - & - & $+3.7 \%$ & $+2.1 \%$ \\
\hline
\end{tabular}

Figure 7 shows the simulated aggregate supply response schedule, which applies to all individuals combined, and an aggregate demand schedule with elasticity $\varepsilon_{d}=0.5$. Figure 8 shows the relevant detail of the earlier figure, focussing on the locality of the intersection. For an inelastic labour demand schedule, the wage effect $\mathbf{i}_{\max }^{*}$ is measured to be around 3.7 per cent (the horizontal distance between the aggregate supply response and supply shift schedules, measured from the point of intersection of the pre-reform labour supply schedule at $\left.\mathbf{i}_{\mathbf{w}}=0\right) .{ }^{23}$ The second scenario assumes that labour demand is responsive to changes in the wage distribution, with an elasticity of 0.5. From Figure 8, we are able to measure the effect of the microsimulated tax policy change on wages and labour supply/demand under the assumption of a clearing labour market. The third-round response combines a simulated increase of 2.07 per cent in the wage distribution, and a reduction of 1.0 per cent in aggregate labour supply.

To summarise the successive effects of a change in the tax system, Table 5 shows the first, second and third round effects of the hypothetical increase from 20 to 25 per cent in the basic rate of income tax, using the January 2000 Australian tax system for the benchmark. The percentage change in income tax revenues, aggregate labour supply and wages at the three stages of simulation described in this paper, are reported. ${ }^{24}$ For the third round effects, results are reported for inelastic labour demand (providing an upper limit to the potential wage response) and for an aggregate demand elasticity of 0.5 (providing a more central simulation of the potential wage response).

The first column of Table 5 shows only the first round effects of the income

\footnotetext{
${ }^{23}$ This is obviously an extreme assumption. Nevertheless, $\mathbf{i}_{\max }^{*}$ provides a useful basis from which to judge the likely wage response to some tax policy reform.

${ }^{24}$ To get third-round estimates of the percentage change in income tax revenues and allowance costs, the simulated shift in the wage distribution is fed back into the detailed behavioural microsimulation process. This produces costs which adjust for the combined behavioural response to the tax increase and the simulated wage effect.
} 
tax increase, with income tax revenues increasing by around 9 per cent. With no behavioural responses factored into the simulation, this is the only effect that a static microsimulation model predicts. The second column includes labour supply responses in the simulation. As reported in earlier sections, labour supply is predicted to reduce on average by 1.9 per cent in response to this tax reform. These behavioural responses have further effects on revenues and costs to the government; the reduction in labour supply results in a lower increase in income tax revenues than in the first-round simulation (from 9.1 per cent to 7.9 per cent). There is an increase in the cost of allowance payments, of around 2.8 per cent, as earnings fall.

The final column of Table 5 shows how the earlier responses might change following potential adjustments in the distribution of wage rates. For a perfectly inelastic labour demand schedule, the shift in aggregate supply results in a proportionate increase of around 3.7 per cent in the distribution of wage rates. Feeding these wage increases back into an adjusted behavioural simulation, income tax revenues rise by 13.4 per cent compared with the status quo. The cost of allowance transfers actually falls by 0.5 per cent, since earnings increase with the adjustment in wages. As expected, aggregate labour supply remains effectively unchanged relative to the status quo, as is implied by the assumption of a fixed level of labour demand. ${ }^{25}$ With an aggregate labour demand elasticity of 0.5 , the adjustment is less extreme. Wage rates are modelled to increase by 2.1 per cent, and aggregate labour supply falls by around 1 per cent overall. These effects combine to generate an increase of 11.7 per cent in the revenue from income tax, and an increase of 0.1 per cent in the cost of allowances.

So far, the results do not disaggregate the sample into demographic or other groups, so the same percentage wage change is applied to all individuals. Our method does not prevent the simulation of disaggregated wage effects, however. Suppose that the labour market comprises high- and low-education workers, with aggregate supply response schedules as shown in Table 2. Suppose further that there exist separate sectoral demands for high- and low-education labour. To illustrate the potential to simulate sectoral wage responses, we parameterise constant-elasticity aggregate demand schedules for high- and low-education workers, with elasticities of 0.3 and 1.0 respectively. ${ }^{26}$ These schedules are shown in the top panel of Table 6 . Separate wage

\footnotetext{
${ }^{25}$ The wage adjustment model sketched here is only one among a range of possible labour market models, many of which include embellishments on the basic clearing labour market assumption (such as search-theoretic models, insider-outsider/efficiency wage/wage curve models which factor unemployment into the market structure). The method proposed in this paper can be extended naturally to alternative models of labour market adjustment.

${ }^{26}$ Again, elasticities are chosen for illustration only. Nevertheless, the choice of elasticities is
} 
effects for each education group may be measured using the approach adopted for the earlier example. Focussing on the two localities of intersection (as shown in the second row of Table 6), the third-round effects of the shift in aggregate supply comprise (i) a 2.3 per cent increase in the wage distribution for high-education workers; (ii) a 1.6 per cent increase in the wage distribution for low-education workers; (iii) a reduction of 0.7 per cent in the demand for high-education labour; and (iv) a 1.6 per cent reduction in aggregate demand for low-education workers. As before, these sectoral wage shifts may be included in an second behavioural simulation in order that simulated government costs and revenues may be adjusted to account for differential supply responses.

\section{Conclusions}

The main aim of this paper has been to extend behavioural microsimulation modelling so that third round effects of a policy change can be simulated; these allow for endogenous changes to the distribution of wage rates resulting from the labour supply responses to tax changes. This has been achieved by the introduction of the concept of the aggregate supply response schedule which identifies the extent to which average labour supply responds to a proportional change in wage rates. Further disaggregation, by using supply response schedules for particular demographic or education groups, provides the possibility of introducing an endogenous change to the form of the distribution of wage rates as well as shifts, since different groups may experience different types of labour supply response to a given tax change, and therefore experience different endogenous wage rate changes.

The use of the concept of the aggregate supply response schedule was illustrated using the behavioural microsimulation model of the Australian economy (MITTS), in which an increase in a marginal income tax rate reduces labour supply in the second round and consequently raises wages. Using a range of assumptions regarding the pattern of aggregate demand, we simulated increases of up to 3.7 per cent in the distribution of wage rates over the sample. After re-running MITTS with a suitable modification to individuals' wage rates, the third-round effects were found to generate substantially larger increases in income tax revenue than were suggested by initial non-behavioural costings. The results demonstrated the potential importance of allowing for such third round effects in microsimulation.

It is suggested that the approach, and the associated concept of the supply re-

consistent with the view of Borjas (2000) that aggregate demand elasticities are typically lower for high-skilled workers than for low-skilled labour. 
Table 6: Disaggregated Supply and Demand Schedules

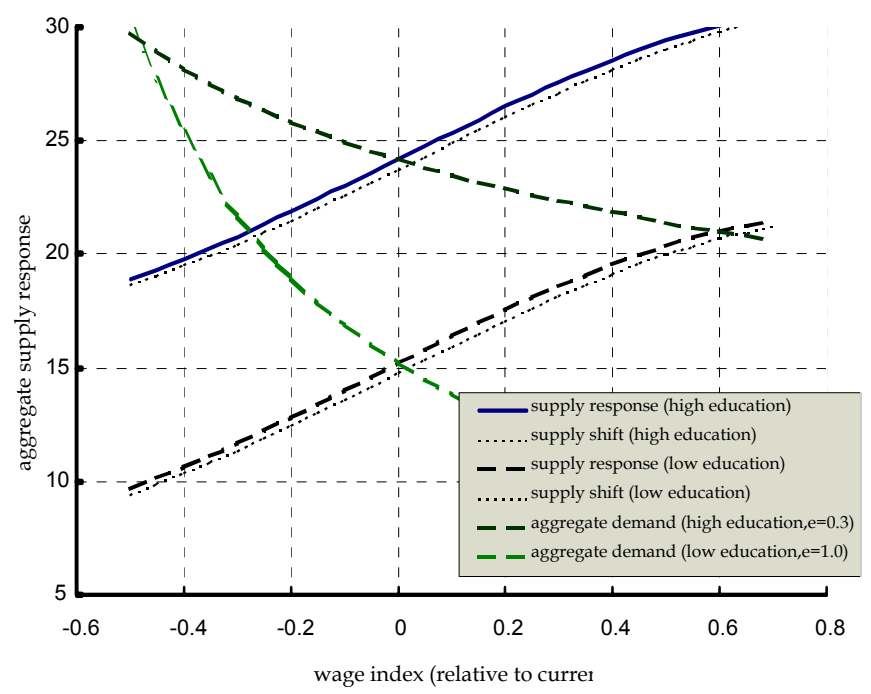

demand and supply - high/low education

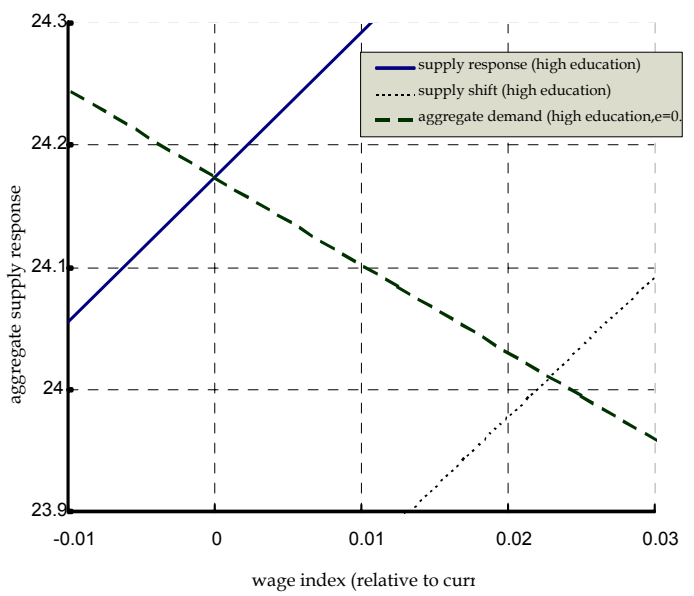

detail - high education

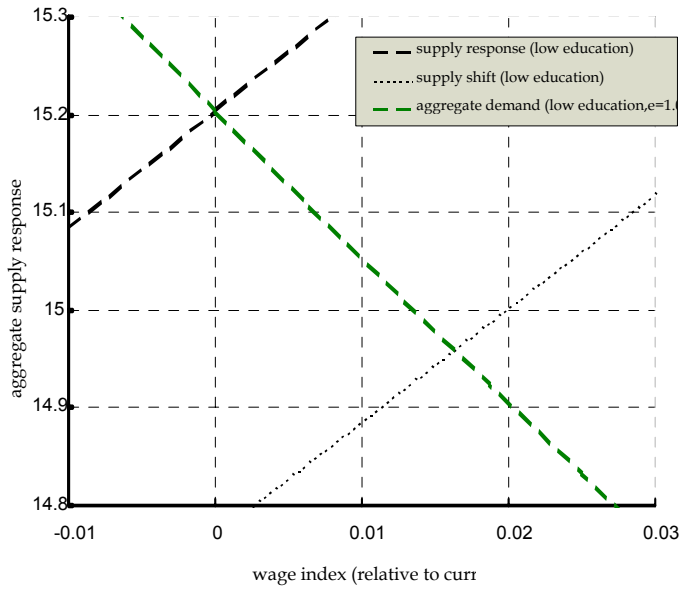

detail - low education 
sponse schedule, can be extended to encompass a wide range of labour market adjustment models. This offers considerable scope for further research. 


\section{References}

[1] Altonji, J.G. (1982) The intertemporal substitution model of labour market fluctuations. Review of Economic Studies, XLIX, pp. 783-824

[2] Altonji, J.G. (1986) Intertemporal substitution in labor supply: evidence from micro data. Journal of Political Economy, 94, pp. s176-s214.

[3] Alogoskoufis, G.S. (1987) On intertemporal substitution and aggregate labor supply. Journal of Political Economy, 95, pp. 938-960.

[4] Ashenfelter, O. (1980) Unemployment as disequilibrium in a model of aggregate labor supply. Econometrica, 48, pp. 547-564.

[5] Bergman, B.R. (1990) Micro-to-macro simulation: a primer with a labor market example. Journal of Economic Perspectives, 4, pp. 99-116.

[6] Borjas, G.J. (2000), Labour Economics (2nd edition), McGraw-Hill.

[7] Creedy, J. and Duncan, A.S. (2001) Behavioural microsimulation with labour supply responses. Journal of Economic Surveys, (forthcoming).

[8] Creedy, J., Duncan, A.S., Harris, M. and Scutella, R. (2002), Microsimulation Modelling of Taxation and the Labour Market: the Melbourne Institute Tax and Transfer Simulator. Cheltenham: Edward Elgar (forthcoming).

[9] Deaton, A. S. and Muellbauer, J. (1980) Economics and Consumer Behaviour. Cambridge: Cambride University Press.

[10] Dilnot, A. and Duncan, A.S. (1992) Lone mothers, family credit and paid work. Fiscal Studies, 13, pp. 1-21.

[11] Duncan, A.S and Harris, M. (2001) Participation and Labour Supply Choices Among Sole Parent Households in Australia, Melbourne Institute Working Paper, April 2001.

[12] Hamermesh, D. (1993) Labour Demand, Princeton, NJ: Princeton University Press

[13] Heckman, J.J. (1993) What has been learned about labor supply in the past 20 years. American Economic Review, 83, 116-121.

[14] Hurwitz, L. and Uzawa, H (1971) On the integrability of demand functions. In Preferences, Utility and Demand (ed. by J.S. Chipman), pp. 174-214. New York: Harcout Brace. 
[15] Keane, M., and Moffitt, R. (1998) A structural model of multiple welfare program participation and labour supply. International Economic Review, 39, pp. 553590.

[16] Kennan, J. (1988) An econometric analysis of fluctuations in aggregate labor suply and demand. Econometrica, 56, pp. 317-333.

[17] Lucas, R.E. and Rapping, L.A. (1969) Real wages, employment and inlation. Journal of Political Economy, 77, pp. 721-754.

[18] Muellbauer, J. (1981) Linear aggregation in neoclassical labour supply. Review of Economic Studies, XLVIII, pp. 21-36.

[19] Stern, N. (1986) On the specification of labour supply functions. In Unemployment, Search and Labour Supply (ed. by R. Blundell and I. Walker), pp. 143-189. Cambridge: Cambridge University Press. 